\title{
Extracorporeal shockwave therapy versus musculoskeletal mesotherapy for Achilles tendinopathy in athlete
}

\author{
Reem EL-Mallah *iD and Enas A. Elattar
}

\begin{abstract}
Background: Achilles tendinopathy (AT) is considered the commonest tendon pathology, occurring mainly in athletes. Different conservative treatment options have been introduced but with short-term effects; however, extracorporeal shockwave therapy (ESWT) and mesotherapy (MT) injections were claimed to provide longer effects and could be used in cases failure of response to conservative treatments.

The objective of our prospective 12-week study was to compare the effect of ESWT and MT on chronic Achilles tendinopathy in athletes by both clinical and ultrasonographical assessment.

Results: Forty patients with chronic AT diagnosed clinically and with high-resolution ultrasound (US) randomly allocated in two groups first received weekly ESWT session, and the other group underwent weekly MT sessions for 4 consecutive weeks. Both groups improved during the treatment and follow-up period. The mean visual analogue score (VAS) decreased in both the ESWT group and the MT group. Mean American Orthopedic Foot and Ankle Society (AOFAS) hindfoot score and VAS scores were not significantly different between ESWT and MT groups at the 4th and the 12th week of follow-up. However, US assessment significantly improved after 12 weeks in the ESWT group (as regards tendon thickness, calcifications, and Doppler signal), and for the mesotherapy group, there was the only improvement of tendon thickness.
\end{abstract}

Conclusion: ESWT showed improvement of pain and inflammation and calcifications of AT than MT injections, which was documented by US improved findings at week 12 follow up.

Keywords: Achilles tendinopathy, Extracorporeal shockwave therapy, Pain, Visual analog scale, Mesotherapy

\section{Background}

Achilles tendon is a strong ligament that conveys both the gastrocnemius and soleus muscles to their calcaneal attachment. The tendon has a fine sheath which is not a synovial one but has a lubrication function. The Achilles tendon is relatively low metabolic tendon getting almost $10 \%$ of its oxygen need from the muscle [1].

Achilles tendinopathy (AT) has been reported to range from 1 to $11 \%$ in athletes [2]. It is a common pathology that occurs mainly in athletes as well as non-athletes, where the cause is usually trauma, overuse injury, or

\footnotetext{
*Correspondence: reemelmallah@gmail.com

Physical Medicine, Rheumatology and Rehabilitation, Faculty of Medicine, Ain Shams University, Cairo, Egypt
}

\section{Springer Open}

repeated minor traumas. The poor vascularity, mechanical de-arrangement, and ankle instability together can contribute to the pathology of the tendon. Diagnosis is mainly by clinical examination, with musculoskeletal ultrasound (US) and magnetic resonance image (MRI) [3].

Tendinopathy could be either insertional or noninsertional (3-4 cm proximal to the calcaneal insertion).

It has various pathological manifestations. In an acute stage, inflammation dominates, with increased neutrophil cell migration, peritendinous edema, local tenderness, and stiffness. In subacute and chronic cases, inflammation seems to play a minor role and complex pathophysiological manifestations such as structural degeneration of the collagen matrix, partial rupture, intra-

(c) The Author(s). 2020 Open Access This article is licensed under a Creative Commons Attribution 4.0 International License, which permits use, sharing, adaptation, distribution and reproduction in any medium or format, as long as you give appropriate credit to the original author(s) and the source, provide a link to the Creative Commons licence, and indicate if changes were made. The images or other third party material in this article are included in the article's Creative Commons licence, unless indicated otherwise in a credit line to the material. If material is not included in the article's Creative Commons licence and your intended use is not permitted by statutory regulation or exceeds the permitted use, you will need to obtain permission directly from the copyright holder. To view a copy of this licence, visit http://creativecommons.org/licenses/by/4.0/. 
tendinous neovascularization, increase neuropeptides, and cell apoptosis [4].

Different lines of management have been introduced for athletes mainly to relieve pain such as eccentric exercises and physical modalities (ultrasound waves, laser, ice); however, the effect of these lines was only shortterm effect. Local injections of long-acting corticosteroids or platelet-rich plasma was also tried in the treatment of Achilles tendinopathy [5].

Shock wave therapy has been introduced to treat different types of soft tissue disorders (plantar fasciitis, elbow epicondylitis, and calcifying rotator cuff tendinopathy) [6] as well as Achilles tendinopathy $[7,8]$.

Low energy extracorporeal shockwave therapy (ESWT) was recommended, with an eccentric exercise program, in patients with chronic Achilles tendinopathy [9]; also, there was a recorded improvement of pain and function on using a high energy ESWT [10].

Mesotherapy (or intradermal therapy) is a series of micro-injections in the upper layers of the skin over the affected part. This depot effect of the skin retains the drug causing slow-release upon which it exerts its action. Recent studies stated that higher drug concentration in skin exerts its effect near the sensory fibers of tissues, vascular mediators of pain and inflammation, where pain is frequently triggered by inflammation of peripheral tissues (nociceptive pain), but it is also associated with a lesion (or dysfunction) in the nerve pathways (neuropathic pain) [11], for which local pharmacological therapy, if it is effective and well-tolerated, is an acceptable alternative to systemic NSAIDs. It has been used for low back pain [12], cervical pain, knee osteoarthritis, and shoulder tendinitis, tendinopathy, and calcific tendinitis [13-16].

\section{Aim of the work}

To compare the effect of extracorporeal shock wave therapy (ESWT) and mesotherapy (MT) on chronic Achilles tendinopathy (AT) in athletes by clinical and ultrasonographical assessment.

\section{Methods}

We started our study with sixty adult athletic patients (non-specific sport) who were chosen from the period of February 2017 till December 2018 diagnosed with chronic Achilles tendinopathy; only forty completed the study till the end.

We calculated the sample size online; on the confidence level of $95 \%$ in a population of 60 patients who were referred to us with a confidence interval (margin of error) of $10 \%$, the calculated ideal sample was 37 patients; we took 40 patients (http://www.qualtrics.com/).
The study was approved by the local department committee and in accordance with the Declaration of Helsinki.

\section{Inclusion criteria}

- Adults with age ranged from 18 to 40 years

- Unilateral chronic AT of 6-12 months with any of these symptoms, tenderness of Achilles tendon during either plantar, dorsiflexion, or in neutral position of the foot. Swelling of tendon (insertional or non-insertional), limited range of motion of the ankle, or disturbed gait (antalgic).

\section{Exclusion of patients}

- With complete tendon tear or with previous surgery for AT, associated fracture, foot deformities, or misalignment

- With previous ESWT or any local injections in the last 3 months

- With skin lesions at tendon (as eczema, psoriasis.

- Under medical treatment NSAIDs, glucocorticoids, or anticoagulants, in the last 2 weeks before intervention.

- With systemic illness, or pregnant females.

- With inflammatory rheumatic diseases especially enthesopathy

Patients were randomly divided into 2 groups for ESWT therapy (group I) and for mesotherapy injections (group II).

\section{Methods}

a. Full clinical history and examination of the patients with stress on clinical symptoms and signs, diseased duration of AT, type of sport (how trauma happened), thickened tendon, localized swelling, signs of inflammation, range of motion of the ankle (both active and passive), and detecting any deformity of the hindfoot (were excluded) or pes planus.

b. Assess pain by visual analog scale (VAS): on a scale ruler of $10 \mathrm{~cm}$ where 0 is no pain and 10 is maximum pain in the last $72 \mathrm{~h}$,

c. Assess function by American Orthopedic Foot and Ankle Society (AOFAS) hindfoot score: which study three dimensions of the hindfoot (pain, function, and alignment) of 100 points [17].

d. Laboratory investigations: to exclude any systemic disorder: Complete blood picture, erythrocyte sedimentation rate, C-reactive protein, serum uric acid, glycosylated hemoglobin, and liver profile and renal profile. 


\section{e. Radiography:}

- -Plain X-ray to foot and ankle: anteroposterior and lateral view, to detect the presence of fracture, deformities, or any of exclusion criteria.

- -Ultrasonography (US) was performed using General Electric Logiq P5 R4.0. with a multi-frequency linear transducer probe 3-12 MHz (General Electric, Milwaukee, Wisconsin, USA). US was performed (greyscale and power Doppler) by a one certified sonographer (blind to the clinical findings and the patient's group) according to EULAR guidelines in both transverse and longitudinal views to confirm a diagnosis of chronic tendinopathy. Greyscale findings may include localized fusiform enlargement, increased tendon thickness $>6 \mathrm{~mm}$, disruption of normal fibrillar striation pattern of tendon, intratendinous hypoechoic areas due to chronic mucoid degeneration, focal calcifications (hyperechoic area). Power Doppler may show increased flow in the intra- and extra-tendinous regions, depending on the grade of inflammation present [18].

\section{Intervention}

Patients of group I received 4 sessions once weekly of high energy ESWT each session consists of 1500 focused shots $0.21 \mathrm{~mJ} / \mathrm{mm}^{2}$ and 3000 radial shots $1.8 \mathrm{~mJ} / \mathrm{mm}^{2}$ using BLT-5000 SWT power shockwave therapy Devise USA, done by the same operator; the session was followed by ice packs to the tendon and eccentric exercises for $15 \mathrm{~min}$. Patients were advised to repeat the exercise at home three times/week.

While patients of group II were injected with a mixture of $5 \mathrm{ml}$ of:

- Two milliliter ampoule of (Betamethasone dipropionate $5 \mathrm{mg}$, Betamethasone sodium phosphate $2 \mathrm{mg}$ ).

- Two milliliters of normal saline $0.9 \%$

- One milliliter of lidocaine $2 \%$

Cleaning the skin with alcohol and using a needle for mesotherapy injections of $(4 \mathrm{~mm} \times 0.4 \mathrm{~mm}$ and $31 \mathrm{G})$ provided by (https://dermatecheg.com) which is commercially available in Egypt. applied to a 5-ml syringe, microinjections are perpendicular to the skin along the sides of the tendon to the depth of $2-4 \mathrm{~mm}$ with a total of 10-15 injections in each side of the tendon each 5 $\mathrm{mm}$ apart, injection starting distally from the site of tendon insertion till the musculotendinous junction proximally $0.2 \mathrm{ml}$ of the mixture per single injection.

The patients received one session weekly for consecutive 4 weeks; all patients tolerated the procedure, with no recorded complications necessitating discontinuation of the further sessions. Patients were advised to do eccentric exercises for $15 \mathrm{~min}$ at home three times/week.

A full detailed explanation of the procedures was offered to the patients, and a written consent was taken from all the participants

The only drug prescribed if needed throughout the 12 weeks was paracetamol for both groups.

\section{Follow-up protocol for both groups}

All patients of both groups were reassessed clinically by VAS and AOFAS and by ultrasound by the same operator at week 4 and week 12 .

\section{Statistical analysis}

Analysis of data was carried out with an IBM computer using statistical program for social science version 18 software and services (released 2009, PASW Statistics for Windows, version 18.0, SPSS Inc., Chicago, IL, USA). Quantitative variables were described as mean, SD, and range. Qualitative variables were described as numbers and percentages. The $\chi^{2}$ test was used to compare qualitative variables between groups. Fisher's exact test was used instead of the $\chi^{2}$ test when one expected cell less than 5. The unpaired $t$ test was used to compare two groups as regards quantitative variables. Paired $t$ test was used to compare two variables quantitative (means) which are measured twice resulting in pairs of observations where $p$ value $<0.05$ is statistically significant [19].

\section{Results}

This prospective study was carried on 40 adult athletes diagnosed clinically and sonographically to have chronic Achilles tendinopathy, they were randomly assigned into 2 groups, and there was no statistically significant difference between the two groups as regards gender, age, and disease duration that was determined by the data analysis as shown in Table 1.

On clinical examination of patients, the pain of ankle and Achilles tendon was reported in all patients (100\%), as well as diffuse swelling of Achilles tendon (43\%) while localized (57\%), tenderness over tendon especially in insertional tendinopathy $(60 \%)$, limited dorsi and plantar flexion (80\%), and disturbed antalgic gait (95\%) of patients.

The dorsiflexors for group I mean was $24.4 \pm 8.4$ and for group II $23.9 \pm 9.1$ with no statistical difference between them before any intervention, and it increased at the 4th week to be $28.4 \pm 5.4$ and $28.4 \pm 1.9$ respectively which is statistically not significantly different. At the 12th week, it was $30.4 \pm 5.9$ and $31.4 \pm 2.4$ for groups I and II respectively which is statistically not significantly different too.

As for plantar flexion in group I, mean was $30.9 \pm 10.5$ and for group II $301.9 \pm 13.5$ with no statistical 
Table 1 Descriptive data of the two groups

\begin{tabular}{|c|c|c|c|c|c|}
\hline Variant & Group I (ESWT) & Group II (mesotherapy) & $x^{2 *}$ & $P$ & $S$ \\
\hline $\operatorname{Sex}(M / F)(N / \%)$ & $16(80 \%) / 4(20 \%)$ & $15(75 \%) / 5(25 \%)$ & 0.000 & 1.000 & NS \\
\hline Age (years) range & & & $0.241 \mathrm{t}$ & 0.811 & NS \\
\hline \multirow[t]{2}{*}{ Mean \pm SD } & $18-39$ & $19-38$ & & & \\
\hline & $35.9 \pm 5.4$ & $34.7 \pm 6.1$ & & & \\
\hline Duration (months) & & & $0.295 t$ & 0.769 & NS \\
\hline \multicolumn{6}{|l|}{ Range } \\
\hline Mean \pm SD & $5.2 \pm 3.5$ & $4.9 \pm 2.9$ & & & \\
\hline $\begin{array}{l}\text { Type of tendinopathy } \\
\text { Insertional/non-insertional } N(\%)\end{array}$ & $11(55 \%) / 9(45 \%)$ & $12(60 \%) / 8(40 \%)$ & 0.000 & 1.000 & NS \\
\hline
\end{tabular}

$M$ male, $F$ female, NS non-significant

${ }^{*}$ Chi-square, $t$; Student's $t$

difference at the start, and it increased at follow-up at the 4th week to be $35.4 \pm 2.4$ and $33 \pm 4.1$ respectively which is statistically not significantly different. At the 12th week, it was $40.4 \pm 6.1$ and $40 \pm 7.2$ for groups I and II respectively which is statistically not significantly different.

On studying the pain improvement by (VAS) for group I, it showed a highly significant decrease of pain at 4 and 12 weeks $\mathrm{P}_{1}$ and $\mathrm{p}_{2}(<0.001)$. A highly significant decrease of pain also was noted in group II at week 4 and week $12 \mathrm{P}_{1}$ and $\mathrm{p}_{2}(<0.001)$. However, there was no statistical difference of VAS values for the two groups initially, at 4 and 12 weeks $\mathrm{P}_{3}(>0.05)$ which is shown in Table 2 and Fig. 1.

On studying the functional improvement using the AOFAS score for group I, it showed a highly significant improvement of function at 4 and 12 weeks $\mathrm{P}_{1}$ and $\mathrm{p}_{2}(<$ 0.001). A highly significant improvement of function also was noted in group II at 4 and 12 weeks $\mathrm{P}_{1}$ and $\mathrm{p}_{2}(<$ 0.001 ). However, there was no statistical difference of AOFAS values for the two groups initially, at week 4 and at week $12 \mathrm{P}_{3}(>0.05)$, which is shown in Table 3 and Fig. 1.

On studying the ultrasonic findings for group I, it showed a significant decrease of tendon thickness at 4 and 12 weeks' follow-up $\mathrm{P}_{1}$ and $\mathrm{p}_{2}(<0.01)$ as well as a significant decrease of tendon thickness of group II at 4 and 12 weeks $P_{1}$ and $p_{2}(<0.01)$. However, there was no statistical difference of tendon thickness values for the two groups initially, at 4 weeks $\mathrm{P}_{3}(>0.05)$, and there was a significant difference at 12th week $P_{3}(<0.05)$, which is shown in Tables 3 and 4 and Figs. 1, 2, 3 and 4.

On studying the heterogenicity of the TA, Doppler activity, and calcification of both groups, there was no statistically significant difference initially between the two groups; however, within group I, there was a statistically significant difference as regards heterogenicity, Doppler activity, and calcifications which was not found in group II as shown in Table 5 and Figs. 3 and 4.

\section{Discussion}

This prospective study aimed to study the effect of both extracorporeal shock wave therapy and mesotherapy injections in chronic Achilles tendinopathy in athletes which is the commonest pathology affecting the Achilles tendon athletes fulfilling the inclusion criteria 31 (77.5\%) were males and 9 (22.5) were females, which is in accordance to other studies who stated that AT is more prevalence in athletes or high activity males mostly with repetitive minor traumas [20]. Clinical and sonographic diagnosis revealed the nature of the tendinopathy as a thickened heterogeneous pattern of the tendon with

Table 2 Comparison between the two groups as regards VAS score initially, at 4 weeks and after 12 weeks

\begin{tabular}{|c|c|c|c|c|c|c|c|}
\hline VAS & Initial & After 4 weeks & After 12 weeks & Paired $\boldsymbol{t}$ test & $\begin{array}{l}\text { Initial-4 weeks } \\
p_{1}\end{array}$ & $\begin{array}{l}\text { Initial-12 weeks } \\
p_{\mathbf{2}}\end{array}$ & $\mathrm{S}$ \\
\hline Group I & $7.51 \pm 1.6$ & $3.92 \pm 2.1$ & $3.10 \pm 2.0$ & $\begin{array}{c}P \text { value } \\
\% \text { of change }\end{array}$ & $\begin{array}{l}<0.001^{*} \\
-47.80 \%\end{array}$ & $\begin{array}{l}<0.001^{*} \\
58.72\end{array}$ & $\mathrm{~S}$ \\
\hline Group II & $7.71 \pm 1.4$ & $4.34 \pm 1.4$ & $4.30 \pm 1.9$ & $\begin{array}{c}P \text { value } \\
\% \text { of change }\end{array}$ & $\begin{array}{l}<0.001^{*} \\
-43.71 \%\end{array}$ & $\begin{array}{l}<0.001^{*} \\
44.23 \%\end{array}$ & S \\
\hline$t$ & 0.403 & 0.734 & 1.935 & & & & \\
\hline$P_{3}$ & 0.682 & 0.4676 & 0.06 & & & & \\
\hline S & Ns & Ns & Ns & & & & \\
\hline
\end{tabular}

VAS visual analog scale. P1, p2, change through time. Paired $t$ test, $\mathrm{P}_{3}$ difference between groups I and II at each time 

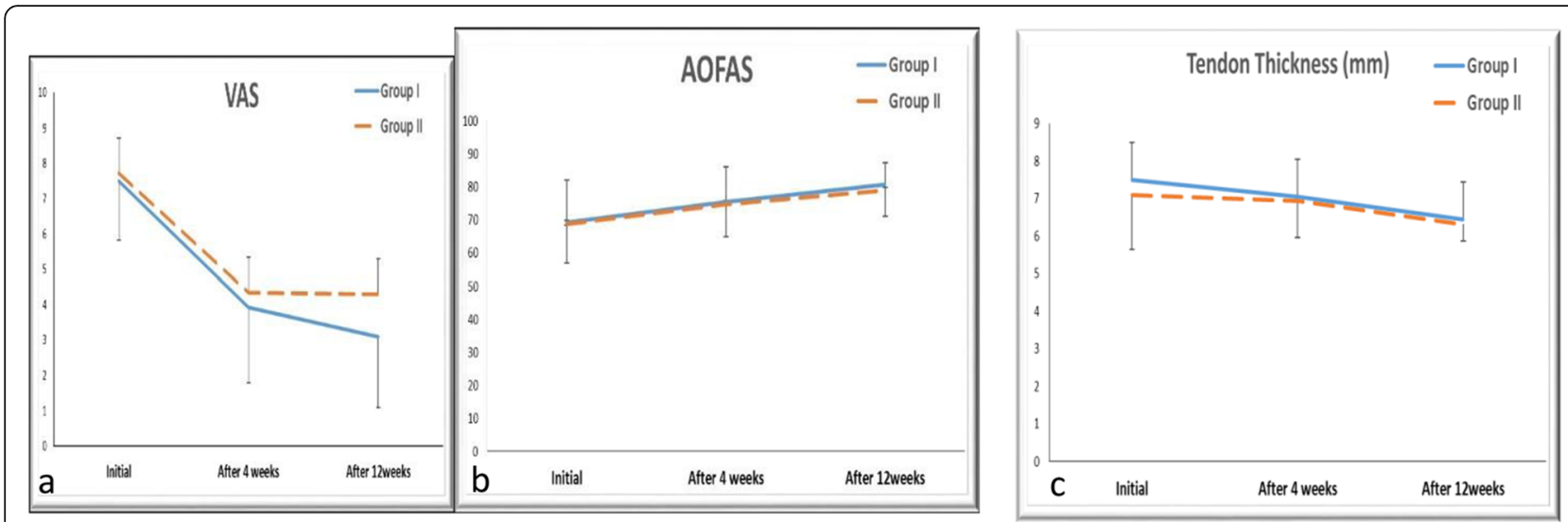

Fig. 1 Blotting values of a VAS, $\mathbf{b}$ AOFAS, and $\mathbf{c}$ tendon thickness initially, at 4 weeks, and at 12 weeks of follow-up

calcifications which is a common picture of tendinopathy. AT is usually presented with pain, swelling which is either insertional or non-insertional and impaired ankle function [21, 22]; our patients were chronic cases of more than 3 months duration which was similar to previous studies who gave eligibility of 3 months or more as main inclusion criterion [10, 12, 22-24]. Initial conservative treatment includes a variety of physical modalities (ice, laser therapy, ultrasound waves, TENS, Shock waves, and exercises). ESWT is one of the most commonly used conservative non-invasive approaches for chronic Achilles tendinopathy treatment. In our study, the group treated with ESWT showed a significant improvement of pain using VAS and ankle function using AOFAS by the 12th week with a significant reduction of the tendon thickness, improved heterogenicity, decreased Doppler signs, and decreased calcifications in both chronic insertional and non-insertional AT [23] which was similar to previous studies that showed a decrease of pain and increased AOFAS score in a group of AT treated with ESWT at weeks 4, 8, and 12 [24]. However, other authors stated that ESWT is effective in patients with non-calcified insertional Achilles tendinopathy while other cases with insertional tendinopathy who are not improving on conservative therapy will need removal of the degenerated part of the calcified tendon [25]. The protocols for ESWT are variably in different studies, ranging from either single session [9], 3-4 sessions [26], weekly or twice weekly [27, 28], with either focused $[7,23,26,27,29-31]$ or radial applications [9, $10,28,32,33$. The number of pulses usually ranges from 1500 to 3000 [28, 31, 32]; our study protocol for ESWT consisted of four weekly sessions of high energy both focused and radial technique, which was similar to other authors [10]. These variable methods of application are trials to establish the optimum biological effect on tendons and soft tissues which is unclear and complex [33, 34]. Earlier studies stated that shock waves may enhance the removal of the damaged matrix of inflamed tendon [34-36]. Other authors hypothesized that ESWT may contribute to the proliferation of collagen fibers and tenocytes, hence enhancing the biological tendon repair $[35,37,38]$ or promoting healing with neovascularization [27] in contrast to our results where we find decreased Doppler signs with follow-up at the 12th week rather than neovascularization. Recently, it is believed that ESWT modifies cell membrane as well as intracellular organs with subsequent nucleus stimulation and the production of specific growth factors that modify different biological repair processes at the site of injury [39].

Table 3 Comparison between two groups as regards AOFAS score initially, at 4 weeks, and after 12 weeks

\begin{tabular}{|c|c|c|c|c|c|c|c|}
\hline AOFAS & Initial & After 4 weeks & After 12 weeks & Paired $\boldsymbol{t}$ test & Initial-4 weeks $p_{1}$ & $\begin{array}{l}\text { Initial-12 weeks } \\
p_{\mathbf{2}}\end{array}$ & S \\
\hline Group I & $69.4 \pm 12.93$ & $75.5 \pm 10.81$ & $80.9 \pm 6.7$ & $\begin{array}{l}P \text { value } \\
\% \text { of change }\end{array}$ & $\begin{array}{l}0.045^{*} \\
8.79\end{array}$ & $\begin{array}{l}0.011^{*} \\
16.57\end{array}$ & $\mathrm{~S}$ \\
\hline Group II & $68.97 \pm 11.97$ & $74.9 \pm 9.98$ & $80.1 \pm 7.8$ & $\begin{array}{l}P \text { value } \\
\% \text { of change }\end{array}$ & $\begin{array}{l}0.048^{*} \\
8.60\end{array}$ & $\begin{array}{l}0.01^{*} \\
14.69\end{array}$ & $\mathrm{~S}$ \\
\hline$t$ & 0.109 & 0.182 & 2.610 & & & & \\
\hline$P_{3}$ & 0.9137 & 0.856 & 0.062 & & & & \\
\hline$S$ & NS & NS & NS & & & & \\
\hline
\end{tabular}


Table 4 The ultrasonic findings of the two groups initially, at 4 weeks and 12 weeks

\begin{tabular}{|c|c|c|c|c|c|c|c|}
\hline $\begin{array}{l}\text { Tendon thickness } \\
\mathrm{mm}\end{array}$ & Initial & 4 weeks & 12 weeks & Paired $\boldsymbol{t}$ test & P1 & P2 & $\mathrm{S}$ \\
\hline Group I & $7.5 \pm 1.68$ & $7.06 \pm 1.05$ & $6.14+0.8$ & $\begin{array}{l}P \text { value } \\
\% \text { of change }\end{array}$ & $\begin{array}{l}0.067 \\
5.87\end{array}$ & $\begin{array}{l}0.01^{*} \\
14.67\end{array}$ & $\mathrm{~S}$ \\
\hline Group II & $7.1 \pm 1.45$ & $6.93 \pm 0.98$ & $6.9 \pm 0.45$ & $\begin{array}{l}P \text { value } \\
\% \text { of change }\end{array}$ & $\begin{array}{l}0.155 \\
2.39\end{array}$ & $\begin{array}{l}0.027^{*} \\
11.13\end{array}$ & $\mathrm{~S}$ \\
\hline $\mathbf{t}$ & 0.806 & 0.405 & 0.633 & & & & \\
\hline p3 & 0.425 & 0.687 & 0.030 & & & & \\
\hline$S$ & NS & NS & S & & & & \\
\hline
\end{tabular}

p1, p2 change through time. Paired $t$ test. P3: difference between groups I and II at each time

${ }^{*} P$ value

Almost all the studies recorded significant pain reduction after ESWT, which was explained by the decrease of substance $\mathrm{p}$ released from the treated area, selective loss of unmyelinated nerve fibers, or activation of the serotonergic system [40, 41]. It was noticed that these biological healing effects of ESWT are not an acute process, but occurring later within weeks after stopping the therapy, and it was recommended to detect the improvement of function after 12 weeks or 16 weeks [24]. Authors mostly use subjective tools for measuring the clinical outcome post ESWT therapy such as VAS [10, $26,28,29]$ and AOFAS [9, 10, 27]. However, ultrasonography was used as an objective tool to detect the treatment outcome $[27,28,42]$ such as the thickness of the tendon, heterogenicity, calcifications, and Doppler signs, where our study outcome was measured objectively with ultrasound documenting the significant change in the tendon thickness, improved heterogenicity, and decreased calcifications and Doppler signs; others stated that ultrasound could not predict the outcome of therapy [42]. Many studies compared the effect of ESWT to Sham ESWT, where they found significant improvement of pain and function in ESWT group [10]; others compared local injections such as corticosteroids [43] where they concluded the pain improves in short-term followup and sodium hyaluronate would be better in the intermediate and long-term follow-up, as mentioned in a study done by Lynen et al. [44], where they found that the usage of two injections of hyaluronan gives a greater improvement of pain than ESWT in cases of Achilles tendinopathy [45]. Platelet-rich plasma was also used in comparison to ESWT in a study done by Erroi et al. [30] where they stated that both modalities are effective for pain and function improvement in a follow-up time of 6 months. In our work, we compared ESWT to local mesotherapy injection (MT), with a clinically significant improvement of pain and tendon function all through the study till the 12th week, as well as significant objective improvement of tendon thickness and heterogenicity and decreased Doppler signs, but in comparison to the group treated with ESWT, no change in calcifications was noticed; however, an old study conducted by $\mathrm{Ca}$ pone et al. [15] using MT (disodium EDTA) to treat patients with calcific shoulder tendinitis found good effect after 24 months' follow-up, as well as another randomized double-blind study of 80 patients with calcific tendinitis of the shoulder, who were treated with mesotherapy one session per week for 1 year, and
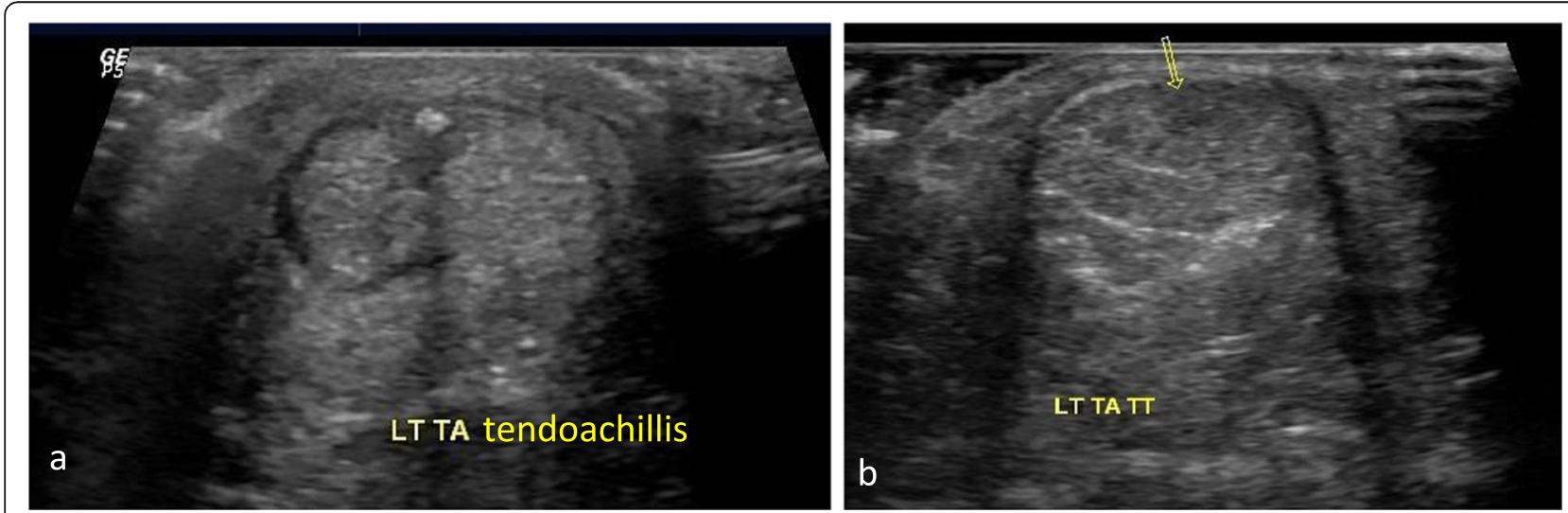

Fig. 2 a Greyscale transverse scan over left Achilles tendon (TA) shows hyperechoic dot of calcification inside the tendon with acoustic shadowing. $\mathbf{b}$ After 12 weeks of treatment with ESWT 
Table 5 Comparison between both groups as regards heterogenicity and PD at 0 week and 12 weeks

\begin{tabular}{|c|c|c|c|c|c|}
\hline Variables & $\begin{array}{l}\text { Group I (ESWT) } \\
\mathbf{N}=20\end{array}$ & $\begin{array}{l}\text { Group II (mesotherapy) } \\
\boldsymbol{N}=20\end{array}$ & $x^{2}$ & $\boldsymbol{P}$ value & S \\
\hline Heterogenicity 0 weeks & & & 1.067 & 0.785 & NS \\
\hline 0 & 0 & 1 & & & \\
\hline 1 & $8(40 \%)$ & $7(35 \%)$ & & & \\
\hline 2 & $7(35 \%)$ & $7(35 \%)$ & & & \\
\hline 3 & $5(25 \%)$ & $5(25 \%)$ & & & \\
\hline Heterogenicity 12 weeks & & & 0.210 & 0.976 & NS \\
\hline 0 & $8(40 \%)$ & 7(35\%) & & & \\
\hline 1 & $7(35 \%)$ & 7(35\%) & & & \\
\hline 2 & $3(15 \%)$ & $4(20 \%)$ & & & \\
\hline 3 & $2(10 \%)$ & $2(10 \%)$ & & & \\
\hline$x^{2}$ & 10.952 & 6.604 & & & \\
\hline $\mathbf{P}$ & $0.012^{*}$ & 0.085 & & & \\
\hline$S$ & S & NS & & & \\
\hline PD 0 weeks & & & 0.00 & 1.00 & NS \\
\hline 0 & $13(65 \%)$ & $12(60 \%)$ & & & \\
\hline 1 & $7(35 \%)$ & $8(40 \%)$ & & & \\
\hline PD after 12 weeks & & & 0.00 & 1.00 & NS \\
\hline 0 & $17(85 \%)$ & 15(75\%) & & & \\
\hline 1 & $3(15 \%)$ & $5(25 \%)$ & & & \\
\hline$x^{2}$ & 0.502 & 0.456 & & & \\
\hline$P$ & $0.023^{*}$ & 0.499 & & & \\
\hline$S$ & S & NS & & & \\
\hline Calcification 0 weeks & & & 0.456 & 0.499 & \\
\hline 0 & $12(60 \%)$ & $15(75 \%)$ & & & \\
\hline 1 & $8(40 \%)$ & $5(25 \%)$ & & & \\
\hline Calcification after 12 weeks & $19(95 \%)$ & $15(75 \%)$ & 1.765 & 0.1840 & \\
\hline 0 & $1(5 \%)$ & $5(25 \%)$ & & & \\
\hline \multicolumn{6}{|l|}{1} \\
\hline$x^{2}$ & 5.161 & 0.00 & & & \\
\hline $\mathbf{P}$ & $0.023^{*}$ & 1.00 & & & \\
\hline$S$ & S & NS & & & \\
\hline
\end{tabular}

PD power Doppler, S significant

placebo for controls showed a disappearance of calcifications completely in $62 \%$ and partially in $25 \%$ of patients treated with MT and 15\% in the control group [16]. Musculoskeletal mesotherapy has been used in shoulder tendinitis using superoxide dismutase in a prospective study of 44 patients where they found $90 \%$ improvement of pain after 5 months' follow-up [13]; it has been used also in tendinopathy in a study by Solinas et al. Using ergotamine in 20 patients in a non-controlled study, they found pain improved when combining mesotherapy with laser therapy [14]. Previous suggested and established rationale for MT are cyclo-oxygenase (COX) inhibitors when using nonsteroidal drugs, thus reducing prostaglandins and other inflammatory mediators and activation of neuronal nitric oxide synthase to produce nitric oxide (NO) causing peripheral antinociception. Another suggested hypothesis for MT is the activation effect of skin cytochrome on the injected analgesic or anti-inflammatory drugs [44].

Given that mesotherapy is based on the inoculation of drugs through multiple microinjections, it is possible that the efficacy recorded in the experimental observations is due not only to the local effect of the drug but also to the action of the needle, or to the combination of both [46]. Many previous studies of MT were conducted on chronic neck pain, comparing the effect of MT with 

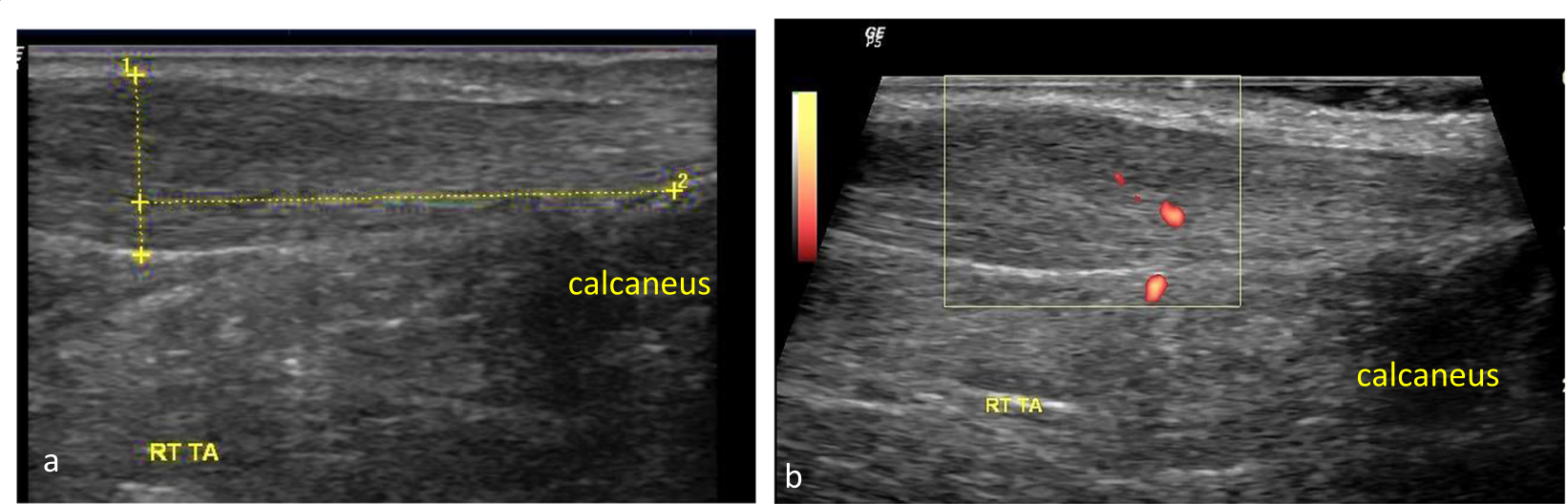

Fig. 3 a Greyscale ultrasound longitudinal scan over right Achilles tendon (TA) shows increased thickness (11 mm) $3.2 \mathrm{~cm}$ away from calcaneus with hypoechoic heterogenicity grade I of fibrillar pattern. $\mathbf{b}$ Power Doppler scan of same patient showing positive PD inside tendon

local anesthetic lidocaine hydrochloride vs dry mesotherapy for 3 sessions showing reduction of pain on VAS scale by the 12th week of the study [47], as well as acute neck pain comparing single injection MT with local anesthetic and steroids vs oral ibuprofen, which showed more analgesic effect than ibuprofen taken orally [48]. Studies on acute back pain (using sterile water microinjections) [49], and in female patients with chronic back pain during labor [50], showed a reduction of pain using VAS score; moreover, studies for chronic spinal pain using weekly MT injection (normal saline, lidocaine $2 \%$ and lysine acetylsalicylate) for 5 weeks showed improved pain and functional outcome [51]; also, in the result of a randomized controlled study of 84 patients with low back pain study using mesotherapy of lidocaine, ketoprofen, and methylprednisolone for 5 sessions and follow-up after 6 months, they found the same effect as systemic drugs given to the control group ( ketoprofen, methylprednisolone, and esomeprazole) [11].

A recent study for knee osteoarthritis showed improvement of pain and functional outcome after 3 months' follow-up reported by Chen et al. [52] comparing the effect of oral diclofenac $150 \mathrm{mg}$ /day to MT ( $2 \mathrm{ml}$ lidocaine, $40 \mathrm{mg}$ piroxicam, and 100 units of calcitonin) for acute knee pain and second protocol of MT (2 ml lidocaine, $2 \mathrm{ml}$ organic silica, and 100 units calcitonin) for chronic knee pain, where they concluded that MT is a safe and effective procedure to decrease pain [53].

Our designed protocol for treating Achilles tendinopathy with MT was not yet typical to other protocols, but of similar drugs used before and in similarity to the conclusions of recent review done by Paolucci et al. [11] where they stated that MT is a good option for pain management, using microinjections either superficial or profound intradermal infusion in the painful area or the trigger points with the specific needle and number and correct dosage of the used drugs, with average sessions ranging from single to 9 sessions and the most used drugs are lidocaine, sterile water, isotonic saline, vitamin B solutions, long-acting corticosteroids, acetylsalicylate, ketorolac, and botulinum toxin.
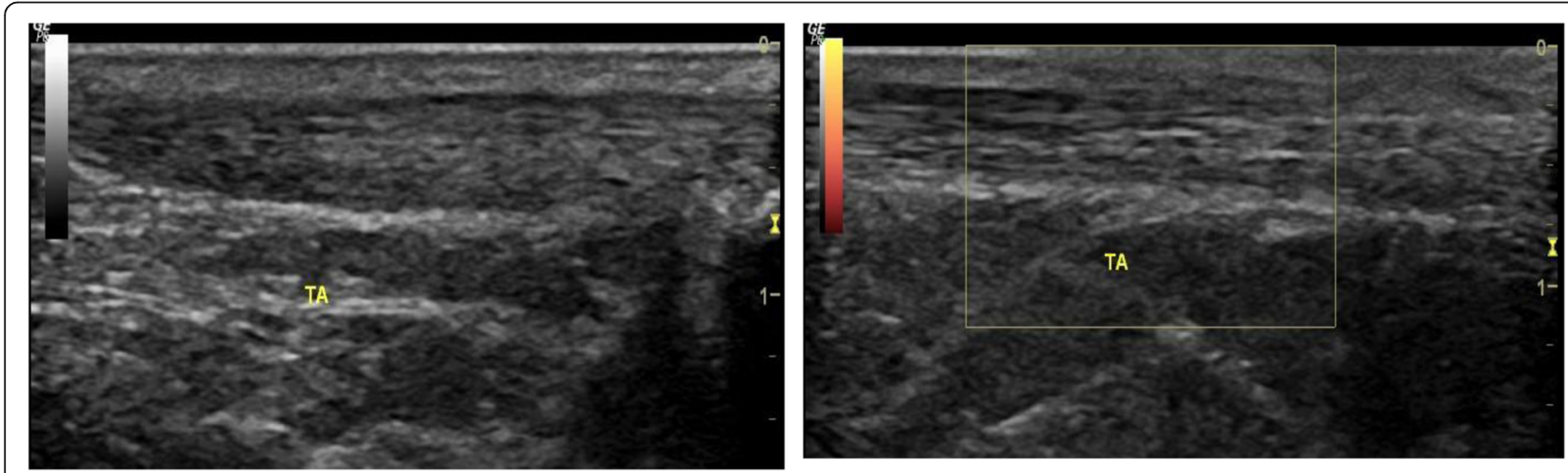

Fig. 4 a Greyscale ultrasound longitudinal scan over right Achilles tendon (TA) post ESWL treatment of above described patients shows improved thickness and heterogenicity of fibrillar pattern. b Power Doppler scan of same patient showing negative PD inside tendon after ESWL 
In our results, the glucocorticoids injected group showed decreased inflammation signs by the 12th week follow-up documented ultrasonographically as decreased Doppler signs.

Both protocol used in our comparative study was followed by $15 \mathrm{~min}$ of eccentric ankle exercises, and patients were advised to repeat it three times per week as it is an effective documented physical intervention for Achilles tendinopathy [52] and it has been associated with clinical benefit in improving pain and function for patients with tendinopathy [54].

Our study was limited by a short duration of follow-up (12 weeks) and a small sample size.

\section{Conclusion}

Chronic Achilles tendinopathy is such a challenging clinical disorder, which needs early accurate objective diagnosis and multidisciplinary intervention. ESWT is a non-invasive well-tolerated technique documented to decreased pain, inflammation, and calcification if present and restore function, whereas mesotherapy injections are micro-invasive very well tolerated as effective as ESWT in pain reduction, decreasing inflammation and restoring function.

We suggest that it is according to initial ultrasound findings; if there are calcifications and severe inflammation, we can use ESWT. If only swelling and heterogeneous tendon, it is preferable to use MT.

In conclusion, any medicine should not be discarded if it showed clinical and objective outcome. Further study is recommended to compare the effect of both modalities with a larger number of patients, and a longer period of follow-up till 24 weeks in different types of sports would have added more value.

\section{Abbreviations}

AT: Achilles tendinopathy; ESWT: Extracorporeal shockwave therapy: MT: Mesotherapy; US: Ultrasound; VAS: Visual analog scale; AOFAS: American Orthopedic Foot and Ankle Society; MRI: Magnetic resonance image

\section{Acknowledgements}

Not applicable

\section{Authors' contributions}

EE gave the idea of the study, was responsible for mesotherapy (preparation, injection, and follow-up), and collected the patients' data and analyze them. RM put the study design, performed the ultrasound, and followed the patients post intervention. Both authors followed up of the group who underwent ESWT. EE wrote the paper with revision. They all approved the final version of the manuscript.

\section{Funding}

This study had no funding from any resource.

\section{Availability of data and materials}

The datasets used and/or analyzed during the current study are available from the corresponding author on reasonable request.

\section{Ethics approval and consent to participate}

This study was approved by the Research Ethics Committee of the Faculty of Medicine at Ain Shams University in Egypt in 2019; the reference number is not available. All patients included in this study gave written informed consent to participate in this research.

\section{Consent for publication}

All patients included in this research gave written informed consent to publish the data contained within this study.

\section{Competing interests}

The authors declare that they have no competing interests.

Received: 16 April 2020 Accepted: 12 July 2020

Published online: 29 December 2020

\section{References}

1. Asplund C, Best T (2013) Achilles tendon disorders. BMJ 346:f1262. https:// doi.org/10.1136/bmj.f1262

2. Freedman B, Gordon J, Soslowsky L (2014) The Achilles tendon: fundamental properties and mechanisms governing healing. Muscles Ligaments Tendons J 4(2):245-255

3. Longo U, Ronga M, Maffulli N (2018) Achilles tendinopathy. Sports Med Arthrosc Rev 26(1):16-30. https://doi.org/10.1097/JSA.0000000000000185

4. Lian O, Scott A, Engebretsen L, Bahr R, Duronio V, Khan K (2007) Excessive apoptosis in patellar tendinopathy in athletes. Am J Sports Med 35:605-611. https://doi.org/10.1177/0363546506295702

5. Diehl P, Gollwitzer H, Schauwecker J, Tischer T, Gerdesmeyer L (2014) Conservative treatment of chronic tendinopathies. Orthopade 43:183-193. https://doi.org/10.1007/s00132-013-2249

6. Michelle W, Jason S (2011) Shock wave therapy for Achilles tendinopathy. Curr Rev Musculoskelet Med 4(1):6-10. https://doi.org/10.1007/s12178-0109067-2

7. Gerdesmeyer L, Mittermayr R, Fuerst M, Al Muderis M, Thiele R, Saxena A, Gollwitzer H (2015) Current evidence of extracorporeal shock wave therapy in chronic Achilles tendinopathy. Int J Surg 24:154-159. https://doi.org/10. 1016/j.ijsu

8. Zamzam M, El Yasaki A, ElGarabawy N, El Ghandour L (2019) Shockwave therapy versus local steroid injection in chronic supraspinatus tendinopathy. Egypt Rheumatol Rehabil 46:141-147. https://doi.org/10.4103/err.err_16_18.

9. Pavone L, Cannavo L, Di Stefano A, Testa G, Costarella L, Sessa G (2016) Low-energy extracorporeal shock-wave therapy in the treatment of chronic insertional Achilles. Tendinopathy: a case series. Biomed Res Int:1-4. https:// doi.org/10.1155/2016/7123769

10. Vahdatpour B, Forouzan H, Momeni F, Ahmadi M, Taheri P (2018) Effectiveness of extracorporeal shockwave therapy for chronic Achilles tendinopathy: a randomized clinical trial. J Res Med Sci 26:23-37. https:// doi.org/10.4103/jrms

11. PaolucciT BR, Centra M, Giannandrea N, Pezzi L, Saggini R (2019) Mesotherapy in the treatment of musculoskeletal pain in rehabilitation: the state of the art. J Pain Res 12:2391-2401. https://doi.org/10.2147/JPR. S209610

12. Costantino C, Marangio E, Coruzzi G. (2011) Mesotherapy versus systemic therapy in the treatment of acute low back pain: a randomized trial. Evidence-Based Complementary and Alternative Medicine.; 6 pages.

13. Biondi G, Romano M, Marcone E, Concetta Meo M, Attanasio L (1985) Orgotein: our experience in rheumatic pathology. Giornale di Mesoterapia 5:25-28

14. Solinas G, Solinas AL, Perra P, Solinas FL (1987) Treatment of mechanical tendinopathies by mesotherapy with ergotamine in combination with laser therapy. Riabilitazione 20(4):281-288.

15. Capone M, Stancati MT, Tolla V, Chiatti R, Muscolo V, Pasquale M (1994) Observations on the administration of sodium edetate in calcified scapulohumeral periarthritis. Ionophoresis and mesotherapy: comparison of two techniques. Ortopedia Traumatologia Oggi 14(4):163-168

16. Cacchio A, De Blasis E, Desiati P, Spacca G, Santilli V, De Paulis F (2009) Effectiveness of treatment of calcific tendinitis of the shoulder by disodium EDTA. Arthritis Care Res 61(1):84-91

17. Taylor J, Dunkerley S, Silver D, Redfern A, Talbot N, Sharp I and Guyver P (2016) Extracorporeal shockwave therapy (ESWT) for refractory Achilles 
tendinopathy: A prospective audit with 2-year follow up presented In: Monitoring Information - Royal Devon and Exeter, NHS, Uk, 27/9/2017.

18. Grechenig W, Clement H, Bratschitsch G, Fankhauser F, Peicha G (2002) Ultrasound diagnosis of the Achilles tendon. Orthopade. 31(3):319-325. https://doi.org/10.1007/s00132-001-0272-y

19. Miller M and Knapp R (1992) Clinical epidemiology and biostatistics in Tulsky D, Skalofske D, Chelune G et, al. (ed), Clinical interpretation of the WAIS-III and WMS-III,3rd edition published by Williams \& Wilkins, Maryland.

20. Singh A, Calafi A, Diefenbach C, Kreulen C, Giza E (2017) Tendinopathy of the Achilles. Foot Ankle Clin 22(4):745-760.280. https://doi.org/10.1016/j.fcl. 2017.07.006

21. Jarvinen T, Kannus P, Maffulli N, Khan K (2005) Achilles tendon disorders: etiology and epidemiology. Foot Ankle:255-266. https://doi.org/10.1016/j.fcl. 2005.01.013

22. Sussmilch-Leitch S, Collins N, Bialocerkowski A, Warden S, Crossley K (2012) Physical therapies for Achilles tendinopathy: systematic review and metaanalysis. Journal of Foot and Ankle Research (5):1-15. https://doi.org/10. 1186/1757-1146-5-15

23. Furia J (2006) High energy extracorporeal shock wave therapy as a treatment for insertional Achilles tendinopathy. Am J Sports Med 34(5):733740. https://doi.org/10.1177/0363546505281810

24. Rasmussen S, Christensen M, Mathiesen I, Simonsen O (2008) Shockwave therapy for chronic Achilles tendinopathy a double-blind, randomized clinical trial of efficacy. Acta Orthop 2:249-256. https://doi.org/10.1080/ 17453670710015058

25. Wiegerinck J, Kerkhoffs G, Van Sterkenburg M, Sierevelt I, Dijk C (2013) Treatment for insertional Achilles tendinopathy: a systematic review. Knee Surg Sport Traumatol Arthrosc (6):1345-1355. https://doi.org/10.1007/ s00167-012-2219-8

26. Furia J (2008) "High-energy extracorporeal shock wave therapy as a treatment for chronic non-insertional Achilles tendinopathy". E. Am J Sports Med 36(3):502-508. https://doi.org/10.1177/0363546507309674

27. Santamato A, Beatrice R, Micello M, Fortunato F, Panza F, Bristogiannis C, Cleopazzo E, Macarini L, Picelli A, Baricich A, Ranieri M (2019) Power Doppler ultrasound findings before and after focused extracorporeal shock wave therapy for Achilles tendinopathy: a pilot study on pain reduction and neovascularization effect. Ultrasound Med Biol 45(5):1316-1323. https://doi org/10.1016/j.ultrasmedbio.2018.12.009

28. Costa M, Shepstone L, Donell S, Thomas T (2005) Shock wave therapy for chronic Achilles tendon pain. Clin Orthop Relat Res 440:199-204. https://doi. org/10.1097/01.blo.0000180451.03425.48

29. Furia J (2006) "High-energy extracorporeal shock wave therapy as a treatment for insertional Achilles tendinopathy," e Am J Sports Med. 2006; (5):733-740. doi.org/https://doi.org/10.1177/0363546505281810.

30. Erroi D, Sigona M, Suarez T, Trischitta D, Pavan A, Vulpiani M, Vetrano M et al (2017) Muscle Ligaments and Tendons Journal 7(1):98-106. https://doi. org/10.11138/mltj/2017.7.1.098

31. Rompe D, Nafe B and Maffulli N (2007) "Eccentric loading, shock-wave treatment, or a wait-and-see policy for tendinopathy of the main body of tendoachillis,". e Am J Sports Med 35(3): 374-383. https://doi.org/10.1177\%2 F0363546506295940

32. Rompe D, Furia j and Maffulli N (2008) "eccentric loading compared with shock wave treatment for chronic insertional Achilles tendinopathy,". Ejournal of Bone and Joint Surgery-American 90(1):52-61. https://doi.org/10. 2106/JBJS.

33. Rompe J, Furia J, Maffulli N (2009) "eccentric loading versus eccentric loading plus shock-wave treatment for midportion Achilles tendinopathy,". E. Am J Sports Med 37(3):463-470. https://doi.org/10.1177/ 0363546508326983

34. Magdalena S, Juras G, Chmielewska D, Polak A, Kucio C and Krol P (2019) Extracorporeal shock wave therapy for Achilles tendinopathy. Biomed Res Int 2019(2):1-13. https://doi.org/10.1155/2019/3086910.

35. Wang C J, (2012) Extracorporeal shockwave therapy in musculoskeletal disorders. J Orthop Surg Res 20; 7:11. https://doi.org/10.1186/1749-799X-7-11.

36. Notarnicola A, Moretti B (2012) The biological effects of extracorporeal shock wave therapy (ESWT) on tendon tissue. Muscle, Ligaments, and Tendons Journal 2(1):33-37 https://www.ncbi.nlm.nih.gov/pmc/articles/ PMC3666498/

37. Romeo P, Lavanga V, Pagani D, Sansone V (2014) Extracorporeal shock wave therapy in musculoskeletal disorders: a review. Med Princ Pract 23(1):7-13. https://doi.org/10.1159/000355472
38. Waugh C, Morrissey D, Jones E, Riley G, Langberg H and Screen H (2015) "In vivo biological response to extracorporeal shockwave therapy in human tendinopathy,". European Cells and Materials 29:268-280. https://doi.org/10. 22203/eCM.v029a20.

39. Vetrano M, D'Alessandro F, Torrisi M, Ferretti A, Vulpiani M, Visco V (2011) Extracorporeal shock wave therapy promotes cell proliferation and collagen synthesis of primary cultured human tenocytes. Knee Surg Sports Traumatol Arthrosc 19(12):2159-2168. https://doi.org/10.1007/s00167-011-1534-9

40. Vitali M, Rodriques N, Pironti P, Drossinos A, Di Carlo G, Chawla A, Gianfranco F (2019) ESWT and nutraceutical supplementation (Tendisulfur forte) vs ESWT-only in the treatment of lateral epicondylitis, Achilles tendinopathy, and rotator cuff tendinopathy: a comparative study. Journal of Drug Assessment 8(1):77-86. https://doi.org/10.1080/21556660.2019. 1605370

41. Wess O (2008) A neural model for chronic pain and pain relief by extracorporeal shock wave treatment. Urol Res 36(6):327-334. https://doi. org/10.1007/s00240-008-0156-2

42. Hausdorf J, LemmensM HK, Grolms N, Korr H, Kertschanska S, Steinbusch H, Schmitz C, Maier M (2008) Selective loss of unmyelinated nerve fibers after extracorporeal shockwave application to the musculoskeletal system. Neuroscience 155(1):138-144. https://doi.org/10.1016/j.neuroscience

43. Cheng $Y$, Zhang J, and Cai Y (2016) "Utility of ultrasonography in assessing the effectiveness of extracorporeal shock wave therapy in insertional Achilles tendinopathy,". Biomed Res Int 1-5. https://doi.org/10.1155/2016/ 2580969.

44. Lynen N, DeVroey T, Spiegel I, Van Ongeval F, Hendrickx N, Stassijns G (2017) Comparison of peritendinous hyaluronan injections versus extracorporeal shock wave therapy in the treatment of painful Achilles' 21 tendinopathy: a randomized clinical efficacy and safety study. Arch Phys Med Rehabil 98(1):64-71. https://doi.org/10.1016/j.apmr.2016.08.470

45. Hart $L$ (2011) Corticosteroid and other injections in the management of tendinopathies: a review. Clin J Sport Med 21(6):540-541. https://doi.org/10. 1097/01.jsm.0000407929.35973.b9

46. Massimo M, Enrica M, Domenico R, Chiara G, Gianpaolo R, et al., (2020) Mesotherapy: From Historical Notes to Scientific Evidence and Future Prospects Scientific World Journal 2020(3542848). https://doi.org/10.1155/ 2020/3542848

47. Mammucari M, Gatti A, Maggiori S, and Sabato A (2012) Role of Mesotherapy in musculoskeletal pain: opinions from the Italian Society of Mesotherapy. Evid Based Complement Alternat Med 2012:1-12. https://doi. org/10.1155/2012/436959.

48. Paolucci T, Piccinini G, Dan Trifan P, Zangrando F, Saracens V (2016) Efficacy of trigger points Mesotherapy for the treatment of chronic neck pain: a short-term retrospective study. Int J Phys Ther Rehab 2:113-118. https://doi. org/10.15344/2455-7498/2016/113

49. Yang XN, Geng ZS, Zhang XL, Zhang YH, Wang XL, Xb Z, Cui JZ (2018) Single intracutaneous injection of local anesthetics and steroids alleviates acute nonspecific neck pain: a CONSORT-perspective, randomized, controlled clinical trial. Medicine (Baltimore) 97(28):e11285. https://doi.org/ 10.1097/MD.0000000000011285

50. Cui JZ, Geng ZS, Zhang YH, Feng JY, Zhu P, Zhang XB (2016) Effects of intracutaneous injections of sterile water in patients with acute low back pain: a randomized, controlled, clinical trial. Braz J Med Biol Res 49(3):1-8. https://doi.org/10.1590/1414-431X20155092

51. Koyucu RG, Demirci N, Yumru AE, Salman S, Ayanoglu YT, Tosun Y, Tayfur C (2018) Effects of intradermal sterile water injections in women with low back pain in labor: a randomized, controlled, clinical trial. Balkan Med J 35 148-154. https://doi.org/10.4274/balkanmedj.2016.0879

52. Chen L, Li D, Zhong J, Qiu B, Wu X (2018) Therapeutic effectiveness and safety of mesotherapy in patients with osteoarthritis of the knee. EvidenceBased Compl Altern Med 4:6513049. https://doi.org/10.1155/2018/6513049

53. Ferrara P, Ronconi G, Viscito R, Pascuzzo R, Radulescu E, Ljoka C, Maggi L, Ferriero G, Foti C (2017) Efficacy of mesotherapy using drugs versus normal saline solution in chronic spinal pain: a retrospective study. Int J Rehabil Res 40(2):171-174. https://doi.org/10.1097/MRR.0000000000000214

54. Maffulli N, Longo UG, Kadaki A, Sipezia F (2019) Achilles tendinopathy. Foot Ankle Surg 19:30052-30059. https://doi.org/10.1016/j.fas.2019.03.009

\section{Publisher's Note}

Springer Nature remains neutral with regard to jurisdictional claims in published maps and institutional affiliations. 